\title{
"Back to the future": a historical perspective on the role of extra-articular reconstruction
}

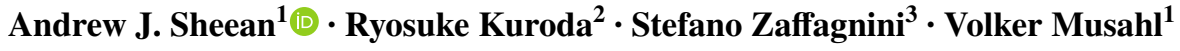

Received: 21 August 2017 / Accepted: 24 August 2017 / Published online: 4 September 2017

(C) European Society of Sports Traumatology, Knee Surgery, Arthroscopy (ESSKA) 2017

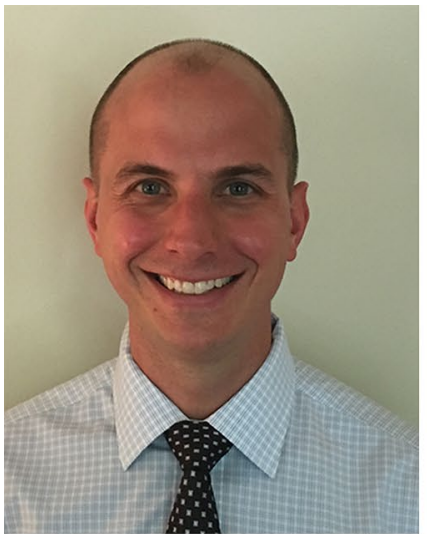

Andrew J. Sheean

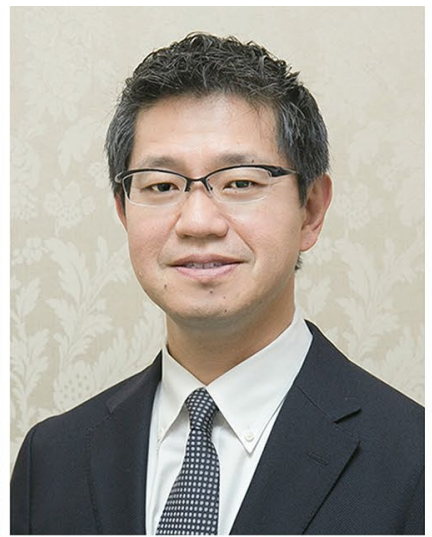

Ryosuke Kuroda

Throughout the last two decades, surgeons debating the optimal surgical strategy to treat the anterior cruciate ligament (ACL)-deficient knee have focused heavily on the intra-articular aspects of surgical reconstruction. Controversies pertaining to transtibial versus anatomic tunnel drilling, optimal graft choice, and single-bundle versus double-bundle reconstructions have been among several of the commonly contested topics among surgeons endeavouring to more perfectly recreate the form and function of the native ACL. However, these controversies notwithstanding,

Andrew J. Sheean

sheeanaj@upmc.edu

1 UPMC Center for Sports Medicine, 3200 S. Water St, Pittsburgh, PA 15203, USA

2 Kobe University Graduate School of Medicine, Kobe University, Kobe, Japan

3 University of Bologna, Bologna, Italy
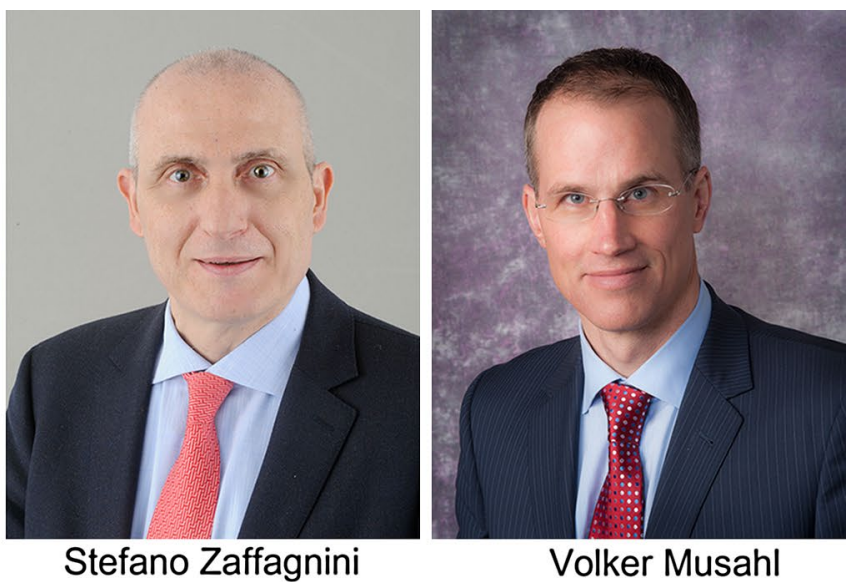

consensus has crystallized around the notion that optimal clinical outcomes may be most closely related to the restoration of rotary knee stability. Perhaps somewhat ironically, we now find ourselves in a similar time to that of Slocum and Larson, who were among the first in 1968-1969 to describe the concept of rotational laxity [25, 26], and Ellison, who in 1980 espoused the importance of extra-articular reconstructions in the setting of lateral tibial plateau subluxation [1].

Although isolated extra-articular procedures are no longer recommended, a myriad of techniques have been described to address what is now a well-accepted notion that injuries to the anterolateral knee structures are important features of the continuum of pathology that manifests as rotary knee laxity in the ACL-deficient knee [2, 3, 18, 20, 23, 29]. Consequently, multiple techniques for lateral extra-articular tenodeses (LET) have been described. First reported in 1967, the original Lemaire technique incorporated a strip of the iliotibial band (ITB) left intact distally at Gerdy's tubercle and passed under the fibular collateral ligament (FCL) before 
being secured to the FCL's femoral insertion via a bone tunnel [9]. Getgood et al. have described a modification to the original Lemaire technique in which the ITB strip is harvested in a manner that maintains the most posterior fibres of the capsule-osseous layer, is fixed to the femur proximally, and then sutured back to itself distally [17]. In the Losee procedure, the ITB is passed anterior to posterior through a femoral tunnel, around the arcuate complex, deep to the FCL, and fixed back to Gerdy's tubercle [10]. Zaffagnini and Marcacci described an intra- and extra-articular arthroscopic ACL reconstruction in which the hamstring tendons are fixed within a groove created in the posterolateral femur and then passed under the fascia, over the FCL, and secured to Gerdy's tubercle [12]. Acknowledging the variability of these techniques in the literature, LET combined with ACL reconstruction has been shown both in vivo and in clinical series to significantly diminish the pivot shift phenomenon $[4,11,13,30,31]$. Thus, it would appear that we have come full circle with our approach to the ACL-deficient knee, as most now acknowledge that special consideration should be given to the status of the peripheral, extra-articular structures of the knee. But which peripheral structures should be addressed?

It is difficult to understate the extent of the scholarly "back-n-forth" among surgeons and anatomists in recent years regarding the anterolateral soft tissues of the knee. Is the anterolateral ligament (ALL) a discrete anatomic structure? Given the heterogeneity of available cadaveric, histologic, and radiographic results related to the ALL, the answer to this question continues to elude us. In this context, one cannot help but wonder "does it even matter if the ALL is a discrete anatomic structure?" But perhaps we are better served by asking, "what are we gaining by focusing so narrowly on the ALL?" In a recent round-table discussion entitled "Contributions of the anterolateral complex and the anterolateral ligament to rotatory knee stability in the setting of ACL injury" published in KSSTA, a collection of preeminent knee surgeons mused over this topic [15]. Although consensus among the panel was not reached, a prevailing sentiment emerged from the dialogue: whether or not we consider ALL a discrete structure or a capsular thickening is secondary to an appreciation for the collective importance of multiple structures that compromise the anterolateral complex (ALC) (ITB and its attachment to the deep capsule-osseous layer, the lateral meniscus, and the ALL_-discrete structure or not). After all, rather compelling evidence suggests that the ITB and its attachment to the deep capsule-osseous layer (so-called Kaplan's fibres) play a critical role in rotary knee stability [8, 22]. Similarly, the status of the lateral meniscus has been shown to affect knee laxity in both cadaveric and in vivo analyses $[14,18]$. Complicating matters further is evidence that abnormalities unrelated to the anterolateral knee soft tissues (increased lateral tibial slope, root tears, and "ramp" lesions of the medial meniscocapsular junction) may contribute to knee laxity as well $[21,27,28]$.

Thus, "ALL myopia" risks an incomplete understanding of why rotary laxity occurs. Rotary knee laxity in the setting of ACL deficiency is infrequently the manifestation of one or two injuries in isolation, but, rather, the result of a constellation of pathology. An appreciation of this fact is critical in determining the optimal surgical tactic for treating injuries associated with high-grade rotatory knee instability in both acute and revision settings as well as in cases of chronic ACL deficiency. Clinical outcome studies have shown variable success in eliminating rotatory knee instability $[19,24$, 30].

Today, LET procedures are commonly considered in the setting of chronic ACL deficiency, revision ACL reconstructions, and/or high-grade rotatory laxity. The first two scenarios are somewhat more intuitive absent any obvious coronal plane malalignment and/or overt technical errors performed at the time of the index ACL reconstruction. However, the features that constitute "high-grade rotatory knee laxity" are certainly less intuitive and, upon further investigation, certainly more subjective. In that same KSSTA round-table discussion mentioned earlier, Williams indicated a preference for adding a LET to a primary ACL reconstruction in the setting of "big pivot shift". Amis echoed these remarks, describing the indication for a LET as "large rotational laxity post-injury" [15]. But what do "big" and "large" pivot shifts feel like? To this end, novel techniques have been proposed that aim at more precisely quantifying the magnitude of tibial subluxation (as a function of absolute tibial translation and acceleration of tibial reduction) during the pivot shift. The PIVOT software application has been found to consistently detect and quantify lateral compartment translation [5]. Moreover, this application has also demonstrated utility in discerning incremental increases in lateral compartment translations associated with increases in clinical grades of pivot shift testing [16]. Similarly, KiRA (KiRA, Orthokey LLC, Lewes, DE) can be used to measure the acceleration of the tibial reduction during the pivot shift, which has been correlated with increasing clinical grades of pivot shift test using an electromagnetic device [6]. Not only do these technologies promise to aid future research efforts to better understand the biomechanical consequences of various LET techniques, but these modalities may also assist surgeons in sharpening their indications for performing LET. While it is possible to make generalizations about which patients are best suited for anterolateral augmentation, the decision to perform a LET is best done on a case-by-case basis, and more precise techniques to measure rotary laxity have the potential to facilitate such an approach. This is an important point given persistent concerns over the untoward consequences of LET, namely over-constraint of tibial rotation and 
the possibility of elevated lateral tibiofemoral contact pressures leading to premature joint arthrosis. Although a recent biomechanical study by Inderhaug and Amis suggests that LET does not lead to significantly increased contact pressures when $20 \mathrm{~N}$ of graft tension was applied with the tibia held in neutral rotation, more research is needed to determine the long-term clinical sequelae of these techniques [7].

While case series have demonstrated the clinical utility of adding LET to ACL reconstruction, prospective, comparative, or even randomized control studies are lacking [30]. This fact underscores the importance of the ongoing, ISAKOS-Sponsored Stability Study of Getgood et al. This multicentre, prospective, randomized clinical trial has enrolled approximately 600 patients. Upon its completion, the data from this trial will undoubtedly help guide decision making as to whom is most likely to benefit from LET. Preliminary results presented at the 2017 11th Biennial ISAKOS Congress on 188 patients suggest that patients undergoing ACL reconstruction alone demonstrated improved results in both assessments of physical performance and patient reported outcome measures. It should be noted that the authors did not specifically report on differences in ACL re-tear rates between groups at 12 months post-operative.

It is through ongoing research efforts such as this that we will continue to correct what Amis lamented as "intraarticular arthroscopic tunnel vision" [15] that so many of us have fallen victim to. The optimal approach to ACL reconstruction remains elusive, but we have made great strides forward in understanding the nature of the problem and the reconstructive solutions best suited to ameliorate the clinical manifestations of the rotationally unstable knee.

\section{Compliance with ethical standards}

Conflict of interest The authors report no disclosures relevant to the publication of this editorial.

Funding No external source of funding was used.

Ethical approval This article does not contain any studies with human participants or animals performed by any of the authors.

\section{References}

1. Ellison AE (1980) The pathogenesis and treatment of anterolateral rotatory instability. Clin Orthop Relat Res 147:51-55

2. Ferretti A, Monaco E, Fabbri M, Maestri B, De Carli A (2017) Prevalence and classification of injuries of anterolateral complex in acute anterior cruciate ligament tears. Arthroscopy 33:147-154

3. Guenther D, Rahnemai-Azar AA, Bell KM, Irarrazaval S, Fu FH, Musahl V, Debski RE (2017) The anterolateral capsule of the knee behaves like a sheet of fibrous tissue. Am J Sports Med 45:849-855

4. Hewison CE, Tran MN, Kaniki N, Remtulla A, Bryant D, Getgood AM (2015) Lateral extra-articular tenodesis reduces rotational laxity when combined with anterior cruciate ligament reconstruction: a systematic review of the literature. Arthroscopy 31:2022-2034

5. Hoshino Y, Araujo P, Ahlden M, Samuelsson K, Muller B, Hofbauer M, Wolf MR, Irrgang JJ, Fu FH, Musahl V (2013) Quantitative evaluation of the pivot shift by image analysis using the iPad. Knee Surg Sports Traumatol Arthrosc 21:975-980

6. Hoshino Y, Kuroda R, Nagamune K, Yagi M, Mizuno K, Yamaguchi M, Muratsu H, Yoshiya S, Kurosaka M (2007) In vivo measurement of the pivot-shift test in the anterior cruciate ligamentdeficient knee using an electromagnetic device. Am J Sports Med 35:1098-1104

7. Inderhaug E, Stephen JM, El-Daou H, Williams A, Amis AA (2017) The effects of anterolateral tenodesis on tibiofemoral contact pressures and kinematics. Am J Sports Med. doi:10.1177/03 63546517717260363546517717260

8. Kittl C, El-Daou H, Athwal KK, Gupte CM, Weiler A, Williams A, Amis AA (2016) The role of the anterolateral structures and the ACL in controlling laxity of the intact and ACL-deficient knee. Am J Sports Med 44:345-354

9. Lemaire M (1975) Chronic knee instability. Technics and results of ligament plasty in sports injuries. J Chir (Paris) 110:281-294

10. Losee RE, Johnson TR, Southwick WO (1978) Anterior subluxation of the lateral tibial plateau. A diagnostic test and operative repair. J Bone Joint Surg Am 60:1015-1030

11. Marcacci M, Zaffagnini S, Giordano G, Iacono F, Presti ML (2009) Anterior cruciate ligament reconstruction associated with extra-articular tenodesis: a prospective clinical and radiographic evaluation with 10- to 13-year follow-up. Am J Sports Med 37:707-714

12. Marcacci M, Zaffagnini S, Iacono F, Neri MP, Loreti I, Petitto A (1998) Arthroscopic intra- and extra-articular anterior cruciate ligament reconstruction with gracilis and semitendinosus tendons. Knee Surg Sports Traumatol Arthrosc 6:68-75

13. Monaco E, Maestri B, Conteduca F, Mazza D, Iorio C, Ferretti A (2014) Extra-articular ACL reconstruction and pivot shift. In vivo dynamic evaluation with navigation. Am J Sports Med 42:1669-1674

14. Musahl V, Citak M, O'Loughlin PF, Choi D, Bedi A, Pearle AD (2010) The effect of medial versus lateral meniscectomy on the stability of the anterior cruciate ligament-deficient knee. Am J Sports Med 38:1591-1597

15. Musahl V, Getgood A, Neyret P, Claes S, Burnham JM, Batailler C, Sonnery-Cottet B, Williams A, Amis A, Zaffagnini S, Karlsson J (2017) Contributions of the anterolateral complex and the anterolateral ligament to rotatory knee stability in the setting of ACL Injury: a roundtable discussion. Knee Surg Sports Traumatol Arthrosc 25:997-1008

16. Musahl V, Griffith C, Irrgang JJ, Hoshino Y, Kuroda R, Lopomo N, Zaffagnini S, Samuelsson K, Karlsson J, PIVOT Study Group (2016) Validation of quantitative measures of rotatory knee laxity. Am J Sports Med 44:2393-2398

17. Musahl V, Karlsson J, Kuroda R, Zaffagnini S (2016) Rotatory knee instability: an evidence based approach. Springer, Heidelberg

18. Musahl V, Rahnemai-Azar AA, Costello J, Arner JW, Fu FH, Hoshino Y, Lopomo N, Samuelsson K, Irrgang JJ (2016) The influence of meniscal and anterolateral capsular injury on knee laxity in patients with anterior cruciate ligament injuries. Am J Sports Med 44:3126-3131

19. Nagai K, Gale T, Herbst E, Tashiro Y, Irrgang JJ, Tashman S, Tashman S, Fu FH, Anderst W (2017) Knee hyperextension does not adversely affect dynamic in vivo kinematics after anterior cruciate ligament reconstruction. Knee Surg Sports Traumatol Arthrosc. doi:10.1007/s00167-017-4653-0

20. Nitri M, Rasmussen MT, Williams BT, Moulton SG, Cruz RS, Dornan GJ, Goldsmith MT, LaPrade RF (2016) An in vitro robotic 
assessment of the anterolateral ligament, part 2: anterolateral ligament reconstruction combined with anterior cruciate ligament reconstruction. Am J Sports Med 44:593-601

21. Peltier A, Lording T, Maubisson L, Ballis R, Neyret P, Lustig S (2015) The role of the meniscotibial ligament in posteromedial rotational knee stability. Knee Surg Sports Traumatol Arthrosc 23:2967-2973

22. Rahnemai-Azar AA, Miller RM, Guenther D, Fu FH, Lesniak BP, Musahl V, Debski RE (2016) Structural properties of the anterolateral capsule and iliotibial band of the knee. Am J Sports Med 44:892-897

23. Rasmussen MT, Nitri M, Williams BT, Moulton SG, Cruz RS, Dornan GJ, Goldsmith MT, LaPrade RF (2016) An in vitro robotic assessment of the anterolateral ligament, part 1: secondary role of the anterolateral ligament in the setting of an anterior cruciate ligament injury. Am J Sports Med 44:585-592

24. Runer A, Wierer G, Herbst E, Hepperger C, Herbort M, Gfoller P, Hoser C, Fink C (2017) There is no difference between quadriceps- and hamstring tendon autografts in primary anterior cruciate ligament reconstruction: a 2-year patient-reported outcome study. Knee Surg Sports Traumatol Arthrosc. doi:10.1007/ s00167-017-4554-2

25. Slocum DB, Larson RL (1968) Pes anserinus transplantation. A surgical procedure for control of rotatory instability of the knee. J Bone Joint Surg Am 50:226-242
26. Slocum DB, Larson RL (1968) Rotatory instability of the knee. Its pathogenesis and a clinical test to demonstrate its presence. $\mathrm{J}$ Bone Joint Surg Am 50:211-225

27. Song GY, Zhang H, Liu X, Zhang J, Xue Z, Qian Y, Feng H (2017) Complete posterolateral meniscal root tear is associated with high-grade pivot-shift phenomenon in noncontact anterior cruciate ligament injuries. Knee Surg Sports Traumatol Arthrosc 25:1030-1037

28. Sonnery-Cottet B, Conteduca J, Thaunat M, Gunepin FX, Seil R (2014) Hidden lesions of the posterior horn of the medial meniscus: a systematic arthroscopic exploration of the concealed portion of the knee. Am J Sports Med 42:921-926

29. Sonnery-Cottet B, Lutz C, Daggett M, Dalmay F, Freychet B, Niglis L, Imbert P (2016) The involvement of the anterolateral ligament in rotational control of the knee. Am J Sports Med 44:1209-1214

30. Sonnery-Cottet B, Thaunat M, Freychet B, Pupim BH, Murphy CG, Claes S (2015) Outcome of a combined anterior cruciate ligament and anterolateral ligament reconstruction technique with a minimum 2-year follow-up. Am J Sports Med 43:1598-1605

31. Trojani C, Beaufils P, Burdin G, Bussiere C, Chassaing V, Djian P, Dubrana F, Ehkirch FP, Franceschi JP, Hulet C, Jouve F, Potel JF, Sbihi A, Neyret P, Colombet P (2012) Revision ACL reconstruction: influence of a lateral tenodesis. Knee Surg Sports Traumatol Arthrosc 20:1565-1570 